(2) Open Access Full Text Article

\title{
Prospective multicenter clinical trial to evaluate the safety and effectiveness of a new glistening- free one-piece acrylic toric intraocular lens
}

This article was published in the following Dove Press journal:

Clinical Ophthalmology

\author{
Mark Packer' \\ Jon I Williams ${ }^{2}$ \\ Gregg Feinerman ${ }^{3}$ \\ Richard S Hope ${ }^{2}$ \\ On behalf of the enVista \\ Toric Clinical Study Group \\ 'Mark Packer MD Consulting, Inc., \\ Boulder, CO, USA; ${ }^{2}$ Surgical Clinical \\ and Medical Affairs, Bausch \& Lomb \\ Inc., Irvine, CA, USA; ${ }^{3}$ Feinerman \\ Vision Center, Newport Beach, \\ CA, USA
}

Purpose: Glistening formation in the intraocular lens (IOL) optic has the potential to impact quality of vision. The enVista One-Piece Hydrophobic Acrylic Spherical IOL Model MX60 (MX60 IOL) is currently the only US Food and Drug Administration-approved IOL with a label of "no glistenings". The purpose of this prospective, multicenter, partially randomized, partially controlled, double-masked, pivotal study was to evaluate the safety and effectiveness of the enVista One-Piece Hydrophobic Acrylic MX60T Toric IOL (enVista MX60T Toric IOL).

Patients and methods: Subjects $(\mathrm{n}=191)$ were implanted with the enVista MX60T Toric IOL (cylinder powers 1.25, 2.00, or 2.75 D) or the parent MX60 IOL (control). Eyes within the lowest range of corneal astigmatism were randomized to receive either Toric 1.25 D IOL or control IOL in a 1:1 ratio. All subjects with corneal astigmatism requiring 2.00 or $2.75 \mathrm{D}$ cylinder IOLs received toric IOLs. Rotational stability, cylinder reduction, and best-corrected distance visual acuity were primary effectiveness endpoints measured at Visit 4 (120-180 days postoperatively).

Results: Visit 4 mean absolute axis misalignment in the All Toric group was $4.68^{\circ} \pm 7.33^{\circ}$, and all subjects had $\leq 5^{\circ}$ absolute rotation from Visit 3 to Visit 4 . The $1.25 \mathrm{D}$ group had significantly greater improvement in dioptric cylinder reduction $(P<0.001)$, percent cylinder reduction $(P<0.001)$, and mean uncorrected distance visual acuity $(P<0.001)$, compared to control at Visit 4. Most adverse events (AEs) were mild, with no serious AEs in the study eyes. The rates of cumulative AEs through Visit 4 were below International Organization for Standardization (ISO) standard 11979-7 AE rates.

Conclusion: enVista MX60T Toric IOL is safe and effective for patients with preoperative corneal astigmatism undergoing IOL implantation.

Keywords: human, IOL, astigmatism, cataract, enVista, clinical

\section{Introduction}

Concomitant treatment of preexisting corneal astigmatism at the time of cataract surgery has become a common goal for patients desiring spectacle independence. It has been estimated that $15 \%-22 \%$ of cataract patients have $>1.50$ diopter (D) of keratometric astigmatism. ${ }^{1,2}$ Additionally, it has been reported that patients are 34 times more likely to use spectacles per diopter of astigmatic error in the better eye, and the residual astigmatism is an important reason for using glasses, even in patients with spherical equivalent refraction \pm 0.50 D. ${ }^{3,4}$ Astigmatism can be corrected by either changing the corneal curvature with LASIK, PRK, incisional keratotomy, or by implanting a toric intraocular lens (IOL). Most surgeons consider correction of astigmatism with toric IOLs to be more predictable, and capable of providing a greater range of corrective power than corneal incisional procedures. ${ }^{5,6}$
Correspondence: Richard S Hope Surgical Clinical and Medical Affairs, Bausch \& Lomb Inc., 50 Technology Drive, Irvine, CA 92618, USA

Tel +l 9493985696

Email richard.hope@bausch.com 
The enVista One-Piece Hydrophobic Acrylic Spherical IOL Model MX60 ([MX60 IOL]; Bausch+Lomb, Inc, Rochester, NY, USA) is a monofocal IOL characterized by an aspheric, aberration-free optic, and scratch-resistant material. The MX60 IOL also has a sharp square edge and posteriorvaulted haptics, two features that have been shown to reduce posterior capsule opacification (PCO) ${ }^{7-9}$ In a pivotal clinical study of the MX60 IOL, ${ }^{8} 100 \%$ of subjects exhibited $\leq 5^{\circ}$ of rotation and achieved 20/40 or better best-corrected distance visual acuity (BCDVA) at Visit 4 (120-180 days postsurgery). The MX60 IOL is currently the only IOL approved by the US Food and Drug Administration with labeling that states that "No glistenings of any grade were reported for any subject at any visit in the clinical study. ${ }^{10}$ " Glistenings are multiple, fluid-filled microvacuoles that form within the substance of an IOL optic. At the slit lamp, light is scattered at the fluid-polymer interface, resulting in a sparkling or "glistenings" appearance. Numerous theories have been proposed for the formation of glistenings, including the gradual absorption of water from the aqueous environment into voids in the polymer network. ${ }^{11}$ Glistenings are important because they may lead to visual problems that can become clinically significant, such as decreased contrast sensitivity at high spatial frequencies ${ }^{12-14}$ or reduced light sensitivities. ${ }^{14}$ The incidence and severity of glistenings may increase over time, ${ }^{13,15}$ which could increase the risk for unwanted side effects. In the extreme, IOLs with glistenings may require explantation. ${ }^{16}$ However, there is no general consensus on the clinical importance of glistenings. ${ }^{16,17}$

The enVista One-Piece Hydrophobic Acrylic MX60T Toric IOL (enVista MX60T Toric IOL) is identical in material composition to the MX60 IOL with the addition of a toric optic and axis marks on the posterior optic surface. The purpose of this prospective, multicenter, partially randomized, partially controlled, double-masked, pivotal study was to evaluate the safety and effectiveness of the enVista MX60T Toric IOL.

\section{Materials and methods Study design and subjects}

This study (NCT01852084 on ClinicalTrials.gov) was conducted at nine sites (10 surgeons) in the USA. For subjects with cataracts in both eyes, the eye with the worse BCDVA at the preoperative visit was designated the study eye. Only one eye per subject was enrolled in the study. The study included subjects with a minimum preoperative corneal astigmatism of 0.90 $\mathrm{D}$ and a predicted postoperative corneal astigmatism between 0.90 and $2.40 \mathrm{D}$, when taking surgically induced astigmatism (SIA) into account. Eyes within the lowest toric cylinder range (0.90-1.39 D at the corneal plane) were randomly assigned to implantation with the $1.25 \mathrm{D}$ toric IOL (enVista MX60T Toric IOL) $0.90 \mathrm{D}$ at the corneal plane or with the control IOL (MX60 IOL) in a 1:1 ratio. All subjects eligible for 2.00 and 2.75 D cylinder toric IOLs (1.40-1.92 D and 1.93-2.40 D at the corneal plane, respectively) received a toric IOL in the study eye. The study was approved by a central Institutional Review Board (The IRB Company, Buena Park, CA, USA) and all subjects provided written informed consent. The study also adhered to the Declaration of Helsinki and good clinical practices as described in International Organization for Standardization (ISO) standard 14155 for study performance.

\section{Presurgical and surgical technique}

The enVista Toric Calculator (Bausch+Lomb) was used to calculate the predicted postoperative corneal astigmatism and the recommended toric IOL cylinder power and axis, using preoperative keratometry and the personalized SIA determined for each investigator. All surgeries were performed using standard small-incision phacoemulsification with the primary incision constructed on the steep keratometric axis.

\section{Criteria for safety and effectiveness evaluation}

The incidences of cumulative and persistent adverse events (AEs) were compared to the ISO 11979-7 AE grid. ${ }^{18}$ All subjects underwent a complete ophthalmic evaluation, including keratometry, biometry, slit-lamp examination, intraocular pressure measurement, and funduscopic examination. To assess AEs such as photophobia, glare, halos, or other visual disturbances, investigators asked patients open-ended questions such as "Has anything changed or is anything bothering you?" Visual acuities (VAs) were tested at $4 \mathrm{~m}$ using a standard Early Treatment Diabetic Retinopathy Study chart at $85 \mathrm{~cd} / \mathrm{m}^{2}$ illumination.

The primary effectiveness endpoints were lens axis misalignment from surgical markings at Visit 4 (Day 120-180 postsurgery), IOL axial stability from Visit 3 (Day 30-60 postsurgery) to Visit 4, reduction in cylinder, BCDVA at Visit 4, and the percentage of eyes within 0.50 and $1.00 \mathrm{D}$ of intended refractive cylinder. The secondary effectiveness endpoint was uncorrected distance visual acuity (UCDVA) at Visit 4. Digital slit-lamp retroillumination photographs were analyzed at a reading center to evaluate IOL rotational stability and analyze posterior capsular opacification with the Evaluation of Posterior Capsular Opacification (EPCO) grading system. ${ }^{19}$

\section{Statistical analysis}

It was planned that $\sim 192$ subjects (192 eyes) would be enrolled (112 eyes with a toric IOL and 80 eyes with the 
control IOL). With estimated subject discontinuation of up to $10 \%$, this enrollment was projected to yield a sample size of completed subjects of at least 72 eyes with a $1.25 \mathrm{D}$ toric IOL, 18 eyes with a $2.00 \mathrm{D}$ toric IOL, 10 eyes with a $2.75 \mathrm{D}$ toric IOL, and 72 eyes with the control IOL.

Primary effectiveness analyses used the intent-to-treat population. Statistical analyses included all subjects who underwent surgery for IOL implantation. For dioptric cylinder reduction from the preoperative visit to Visit 4, after imputation for missing values, the statistical hypothesis for difference between the randomized treatment groups was tested using Type II analyses from general linear models including the effects of treatment and investigator. Reduction of cylinder expressed as a percentage of the intended reduction of cylinder (as described in the American National Standards Institute standard Z80.30:2006 ${ }^{20}$ ) was calculated as ([postoperative manifest refractive cylinder]-[preoperative Delta $\mathrm{K}]) /([$ intended postoperative manifest refractive cylinder][preoperative Delta K]), where postoperative manifest refractive cylinder was converted to the corneal plane assuming a vertex distance of $13 \mathrm{~mm}$. BCDVA at Visit 4 was compared between the control and toric 1.25 D IOL groups using twosample, two-sided $t$-tests with two-sided exact binomial $90 \%$ CI around the proportion of eyes 20/40 or better. After imputation for missing logMAR (logarithm of the minimum angle of resolution) UCDVA values, the UCDVA statistical hypothesis for difference between randomized treatment groups was tested by Type II analyses from general linear models including the effects of treatment and investigator.

Safety analyses were conducted with the safety population (all subjects who underwent surgery). If a subject had multiple visits within a visit window, then safety summaries included the worst case observations in the window. For each ISO standard $11979-7^{18}$ grid AE, a one-sided exact binomial test comparing the proportion of toric IOL eyes with the AE to the relevant control rate was conducted. If the resulting $P$-value was $\leq 0.05$, then the null hypothesis was rejected. Fisher's exact test was used to compare the proportion of AEs among groups. All statistical measures required $P<0.05$ for significance.

\section{Results}

\section{Demographics and baseline characteristics}

A total of 191 subjects were enrolled in this study, with 79 subjects in the control IOL group and 112 subjects receiving a toric IOL ( 80 subjects in the $1.25 \mathrm{D}$ group, 20 subjects in the $2.00 \mathrm{D}$ group, and 12 subjects in the $2.75 \mathrm{D}$ group). The percentage of eyes receiving a control IOL vs a toric
1.25 D IOL was stratified by site and was approximately equal across sites. The demographics and baseline characteristics of the subjects are presented in Table 1 . The mean \pm SD age of the study population was $70.1 \pm 8.7$ years. The population was primarily White $(96.3 \%)$, and the $1.25 \mathrm{D}$ toric IOL group had proportionally more women than the control IOL group (61.3\% vs $45.6 \%)$. The mean axial length, calculated IOL spherical power, and target refraction were all similar between the control and toric IOL treatment groups. Most study eyes in each treatment arm $(>96 \%)$ had either moderate or dense cataracts preoperatively, and all eyes had normal corneal topography.

\section{Safety}

A total of $48.1 \%$ of subjects in the control IOL group and $42.9 \%$ of subjects in the All Toric group had AEs in the study eye. The most frequently reported AEs were corneal edema including wound edema (control group: 19.0\% of eyes; All Toric group: $18.8 \%$ of eyes) and anterior chamber cells (control: 19.0\% of eyes, All Toric: 18.8\% of eyes). Ocular AEs are shown for the safety population in Table 2. The majority of AEs (79.3\%) were mild, and there were no serious AEs in the study eye of any subject. There were also no device-related AEs or AEs leading to subject premature discontinuation from the study. All subjects except for two subjects in the $2.00 \mathrm{D}$ group completed the study; one subject discontinued because of a withdrawal of consent, and one subject was lost to follow-up after Visit 3. The rates of all cumulative or persistent AEs through Visit 4 for all toric IOLs were below the ISO standard 11979-7 historical AE grid rates (Table 2). The only persistent AE for subjects with no imputation was a single case of cystoid macular edema in the control IOL group.

\section{Efficacy}

\section{Rotational stability}

At Visit $4,>90 \%$ of eyes in each toric IOL group had misalignments of $\leq 10^{\circ}$ from surgical marking (Table 3). Mean absolute axis misalignment among all toric IOL eyes was $4.68^{\circ} \pm 7.33^{\circ}$ at Visit 4 . Two subjects with $1.25 \mathrm{D}$ toric IOLs had $>30^{\circ}$ lens axis misalignment at Visit 1 and minimal rotation thereafter. UCDVA at Visit 4 was 20/25 and 20/40 for these two subjects, respectively, and neither subject required secondary IOL repositioning.

Absolute IOL rotation from Visit 3 to Visit 4 showed that each toric IOL group had a mean absolute rotation of $\leq 1.15^{\circ}$. Additionally, $100 \%$ of eyes implanted with toric IOLs had $\leq 5^{\circ}$ of rotation (Table 3 ). 
Table I Subject demographics and baseline characteristics

\begin{tabular}{|c|c|c|c|c|c|}
\hline & \multirow{3}{*}{$\begin{array}{l}\text { Control } \\
\text { IOL } \\
(\mathrm{N}=79)\end{array}$} & \multicolumn{3}{|l|}{ Toric IOL } & \multirow{3}{*}{$\begin{array}{l}\text { All toric } \\
\text { lenses } \\
(N=|| 2)\end{array}$} \\
\hline & & \multirow{2}{*}{$\begin{array}{l}.25 \mathrm{D} \\
(\mathrm{N}=80)\end{array}$} & \multirow{2}{*}{$\begin{array}{l}2.00 \mathrm{D} \\
(\mathrm{N}=20)\end{array}$} & \multirow{2}{*}{$\begin{array}{l}2.75 \mathrm{D} \\
(\mathrm{N}=12)\end{array}$} & \\
\hline & & & & & \\
\hline \multicolumn{6}{|l|}{ Gender at birth, n (\%) } \\
\hline Male & $43(54.4)$ & $31(38.8)$ & $12(60.0)$ & $3(25.0)$ & $46(4 I . I)$ \\
\hline Female & $36(45.6)$ & $49(61.3)$ & $8(40.0)$ & $9(75.0)$ & $66(58.9)$ \\
\hline \multicolumn{6}{|l|}{ Age (years) } \\
\hline Mean (SD) & $69.5(8.6)$ & 7I.I (8.8) & $68.7(9.1)$ & $69.6(8.8)$ & $70.5(8.9)$ \\
\hline Min, Max & 52,87 & 40,89 & 58,86 & 56,85 & 40,89 \\
\hline \multicolumn{6}{|l|}{ Race, n (\%) } \\
\hline White & $76(96.2)$ & $79(98.8)$ & I8 (90.0) & II (9I.7) & $108(96.4)$ \\
\hline Black/African American & 0 & 0 & $2(10.0)$ & I (8.3) & $3(2.7)$ \\
\hline Asian & $\mathrm{I}(\mathrm{I} .3)$ & $\mathrm{I}(\mathrm{I} .3)$ & 0 & 0 & $\mathrm{I}(0.9)$ \\
\hline Other & $2(2.5)$ & 0 & 0 & 0 & $0(0.0)$ \\
\hline \multicolumn{6}{|l|}{ Ethnicity, n (\%) } \\
\hline Hispanic or Latino & $4(5.1)$ & $\mathrm{I}(\mathrm{I} .3)$ & $2(10.0)$ & 0 & $3(2.7)$ \\
\hline Not Hispanic, not Latino & $75(94.9)$ & $79(98.8)$ & $18(90.0)$ & $12(100.0)$ & $109(97.3)$ \\
\hline \multicolumn{6}{|l|}{ Cataract density, n (\%) } \\
\hline Slight (I+) & $\mathrm{I}(\mathrm{I} .3)$ & $\mathrm{I}(\mathrm{I} .3)$ & 0 & 0 & $\mathrm{I}(0.9)$ \\
\hline Moderate $(2+)$ & $41(51.9)$ & $42(52.5)$ & $16(80.0)$ & $9(75.0)$ & $67(59.8)$ \\
\hline Dense $(3+)$ & $35(44.3)$ & $36(45.0)$ & $4(20.0)$ & $3(25.0)$ & $43(38.4)$ \\
\hline Very dense (4+) & $2(2.5)$ & $\mathrm{I}(\mathrm{I} .3)$ & 0 & 0 & $\mathrm{I}(0.9)$ \\
\hline \multicolumn{6}{|c|}{ Potential visual acuity testing, $\mathrm{n}(\%)$} \\
\hline $20 / 20$ or better & $39(59.1)$ & $29(43.9)$ & $3(15.0)$ & $4(33.3)$ & $36(36.7)$ \\
\hline $20 / 25$ & $27(40.9)$ & $37(56.1)$ & $17(85.0)$ & $8(66.7)$ & $62(63.3)$ \\
\hline Not reported & 13 & 14 & 0 & 0 & 14 \\
\hline \multicolumn{6}{|l|}{ Targeted refraction, $D$} \\
\hline Mean (SD) & $-0.115(0.139)$ & $-0.095(0.135)$ & $-0.117(0.156)$ & $-0.178(0.089)$ & $-0.108(0.136)$ \\
\hline Min, Max & $-0.46,0.45$ & $-0.32,0.28$ & $-0.49,0.24$ & $-0.30,-0.03$ & $-0.49,0.28$ \\
\hline \multicolumn{6}{|c|}{ Calculated spherical equivalent IOL power (D) } \\
\hline Mean (SD) & $20.32(2.21)$ & $20.72(2.23)$ & $21.88(3.28)$ & $18.96(2.67)$ & $20.74(2.58)$ \\
\hline Min, Max & $16.0,25.0$ & $16.0,26.0$ & $16.0,27.0$ & $16.0,24.0$ & $16.0,27.0$ \\
\hline \multicolumn{6}{|l|}{ Axial length (mm) } \\
\hline Mean (SD) & $23.739(0.845)$ & $23.621(0.748)$ & $23.321(1.124)$ & $24.207(0.936)$ & $23.630(0.869)$ \\
\hline Min, Max & $21.77,26.14$ & $20.95,25.40$ & $21.49,25.73$ & $22.79,26.14$ & $20.95,26.14$ \\
\hline \multicolumn{6}{|l|}{ Keratometric cylinder (D) } \\
\hline Mean (SD) & $1.566(0.159)$ & $1.547(0.166)$ & $1.991(0.14 I)$ & $2.590(0.179)$ & $1.738(0.378)$ \\
\hline Min, Max & $\mathrm{I} .05,2.0 \mathrm{I}$ & $1.24,1.88$ & I.7I, 2.18 & $2.36,2.86$ & $1.24,2.86$ \\
\hline \multicolumn{6}{|l|}{ BCDVA, logMAR } \\
\hline Mean (SD) & $0.482(0.228)$ & $0.504(0.195)$ & $0.584(0.365)$ & $0.517(0.211)$ & $0.520(0.235)$ \\
\hline Min, Max & $0.20,1.48$ & $0.26,1.38$ & $0.30,1.60$ & $0.30,1.00$ & $0.26,1.60$ \\
\hline \multicolumn{6}{|l|}{ UCDVA, logMAR } \\
\hline Mean (SD) & $0.633(0.335)$ & $0.616(0.279)$ & $0.720 *(0.377)$ & $0.727(0.304)$ & $0.644(0.300)$ \\
\hline Min, Max & $0.10,1.54$ & $0.12,1.46$ & $0.04,1.50$ & $0.30,1.46$ & $0.04,1.50$ \\
\hline
\end{tabular}

Notes: ${ }^{*} n=17$; three subjects could not report UCDVA because they could only count fingers.

Abbreviations: BCDVA, best-corrected distance visual acuity; D, diopter; IOL, intraocular lens; logMAR, logarithm of the minimum angle of resolution; Max, maximum; Min, minimum; UCDVA, uncorrected distance visual acuity.

\section{Reduction in cylinder}

As shown in Table 4, the $1.25 \mathrm{D}$ toric IOL group had significantly greater mean cylinder reduction at Visit 4 compared with the control IOL group. The mean dioptric cylinder reduction was $0.479 \pm 0.665 \mathrm{D}$ for control IOLs, $0.865 \pm 0.487 \mathrm{D}$ for $1.25 \mathrm{D}$ toric IOLs, $1.413 \pm 0.532 \mathrm{D}$ for $2.0 \mathrm{D}$ toric IOLs, and $1.944 \pm 0.327 \mathrm{D}$ for $2.75 \mathrm{D}$ toric IOLs. The cylinder reduction in the control group is likely due to the study requirement to place the primary corneal incision on the steep axis. Nevertheless, the treatment effect between the $1.25 \mathrm{D}$ Toric group and the control group was statistically significant at $0.39 \mathrm{D}(P<0.001)$. Evaluation of these data stratified by age, race, or gender showed no significant interaction with any of these variables.

In terms of accuracy to the refractive target, cylinder reduction within $0.50 \mathrm{D}$ of intended reduction at Visit 4 was 
Table 2 Ocular adverse events in the safety population $(n=|9|)$ and cumulative or persistent adverse events identified in the ISO standard II979-7 SPE grid through Visit 4

\begin{tabular}{|c|c|c|c|c|c|}
\hline & \multirow{2}{*}{$\begin{array}{l}\text { Control } \\
\text { IOL } \\
(\mathbf{N}=79)\end{array}$} & \multicolumn{4}{|l|}{ Toric IOL } \\
\hline & & $\begin{array}{l}\text { I.25 D } \\
(\mathrm{N}=80)\end{array}$ & $\begin{array}{l}2.00 \mathrm{D} \\
(\mathrm{N}=20)\end{array}$ & $\begin{array}{l}2.75 \mathrm{D} \\
(\mathrm{N}=12)\end{array}$ & $\begin{array}{l}\text { All Toric } \\
(\mathrm{N}=I \mid 2)\end{array}$ \\
\hline One or more adverse events & 38 (48.1\%) & 39 (48.8\%) & 7 (35.0\%) & $2(16.7 \%)$ & $48(42.9 \%)$ \\
\hline Eye disorders & 35 (44.3\%) & $35(43.85)$ & $7(35.0 \%)$ & $2(16.7 \%)$ & $44(39.3 \%)$ \\
\hline Corneal edema & 15 (19.0\%) & 18 (22.5\%) & $3(15.0 \%)$ & 0 & 21 (I8.8\%) \\
\hline Anterior chamber cell & $17(21.5 \%)$ & 15 (18.8\%) & I (5.0\%) & I (8.3\%) & $17(I 5.2 \%)$ \\
\hline Anterior chamber flare & $4(5.1 \%)$ & $3(3.8 \%)$ & I (5.0\%) & I (8.3\%) & $5(4.5 \%)$ \\
\hline Punctate keratitis & $6(7.6 \%)$ & $5(6.3 \%)$ & 0 & 0 & $5(4.5 \%)$ \\
\hline Visual acuity reduced & 7 (8.9\%) & $2(2.5 \%)$ & I (5.0\%) & I (8.3\%) & $4(3.6 \%)$ \\
\hline Dry eye & $\mathrm{I}(1.3 \%)$ & $\mathrm{I}(1.3 \%)$ & $2(10.0 \%)$ & 0 & $3(2.7 \%)$ \\
\hline Corneal abrasion & 0 & $2(2.5 \%)$ & 0 & 0 & $2(1.8 \%)$ \\
\hline Cystoid macular edema & $2(2.5 \%)$ & $2(2.5 \%)$ & 0 & 0 & $2(1.8 \%)$ \\
\hline Diplopia & 0 & $\mathrm{I}(\mathrm{I} .3 \%)$ & 1 & 0 & $2(1.8 \%)$ \\
\hline Trichiasis & 0 & $\mathrm{I}(1.3 \%)$ & 1 & 0 & $2(1.8 \%)$ \\
\hline Anterior capsule contraction & 0 & $\mathrm{I}(\mathrm{I} .3 \%)$ & 0 & 0 & I (0.9\%) \\
\hline Cataract operation complication & 0 & I (I.3\%) & 0 & 0 & I (0.9\%) \\
\hline Corneal disorder & 0 & $\mathrm{I}(\mathrm{l} .3 \%)$ & 0 & 0 & I (0.9\%) \\
\hline Eye pain & 0 & $\mathrm{I}(\mathrm{I} .3 \%)$ & 0 & 0 & I (0.9\%) \\
\hline Iris atrophy & 0 & I (I.3\%) & 0 & 0 & I (0.9\%) \\
\hline Keratitis & 0 & I (I.3\%) & 0 & 0 & I (0.9\%) \\
\hline Maculopathy & 0 & 0 & I (5.0\%) & 0 & I (0.9\%) \\
\hline Photophobia & 0 & 0 & I (5.0\%) & 0 & I (0.9\%) \\
\hline Toxic anterior segment syndrome & 0 & $\mathrm{I}(\mathrm{I} .3 \%)$ & 0 & 0 & I (0.9\%) \\
\hline Conjunctivitis & $\mathrm{I}(\mathrm{I} .3 \%)$ & 0 & 0 & 0 & 0 \\
\hline Iritis & I (I.3\%) & 0 & 0 & 0 & 0 \\
\hline Retinal tear & $\mathrm{I}(1.3 \%)$ & 0 & 0 & 0 & 0 \\
\hline Investigations & $3(3.8 \%)$ & $5(6.3 \%)$ & I (5.0\%) & 0 & $6(5.4 \%)$ \\
\hline \multirow[t]{2}{*}{ Intraocular pressure increased } & $3(3.8 \%)$ & $5(6.3 \%)$ & $\mathrm{I}(5.0 \%)$ & 0 & $6(5.4 \%)$ \\
\hline & $\begin{array}{c}\text { Control } \\
\text { IOL } \\
(\mathbf{N}=79)\end{array}$ & $\begin{array}{r}\text { All Toric } \\
(\mathbf{N}=I \mid 2)\end{array}$ & & $\begin{array}{r}\text { ISO grid } \\
\text { historical } \\
\text { controls }\end{array}$ & $P$-value ${ }^{a}$ \\
\hline \multicolumn{6}{|l|}{ Cumulative AEs } \\
\hline Endophthalmitis & 0 & 0 & & $0.1 \%$ & $>0.999$ \\
\hline Hypopyon & 0 & 0 & & $0.3 \%$ & $>0.999$ \\
\hline Lens dislocated from posterior chamber & 0 & 0 & & $0.1 \%$ & $>0.999$ \\
\hline Cystoid macular edema & $2(2.5 \%)$ & $2(1.8 \%)$ & & $3.0 \%$ & 0.853 \\
\hline Pupillary block & 0 & 0 & & $0.1 \%$ & $>0.999$ \\
\hline Retinal detachment & 0 & 0 & & $0.3 \%$ & $>0.999$ \\
\hline Secondary surgical intervention & 0 & 0 & & $0.8 \%$ & $>0.999$ \\
\hline \multicolumn{6}{|l|}{ Persistent AEs } \\
\hline Cystoid macular edema & I (I.3\%) & 0 & & $0.5 \%$ & $>0.999$ \\
\hline Corneal stroma edema & 0 & 0 & & $0.3 \%$ & $>0.999$ \\
\hline Iritis & 0 & 0 & & $0.3 \%$ & $>0.999$ \\
\hline $\begin{array}{l}\text { Raised intraocular pressure requiring } \\
\text { treatment }\end{array}$ & 0 & 0 & & $0.4 \%$ & $>0.999$ \\
\hline
\end{tabular}

Notes: Adverse events are sorted in order of descending frequency for the all Toric lens category by system, organ, class, and preferred term. ${ }^{\mathrm{a} T h e} P$-value was calculated from the exact binomial test comparing the cumulative proportion of all toric IOL eyes with each AE to the ISO II 979-7 AE grid proportion (one-sided test).

Abbreviations: AE, adverse event; D, diopter; IOL, intraocular lens; ISO, International Organization for Standardization; SPE, safety and performance endpoints.

substantially better in the All Toric group (57.3\%) than in the control IOL group (34.6\%). Further, cylinder reduction within $1.00 \mathrm{D}$ of intended reduction was achieved by $90.9 \%$ of eyes in the All Toric group compared to only $57.7 \%$ of eyes in the control IOL group (Table 4).

The comparison of dioptric reduction in cylinder between treatments was adjusted for the effect of site because of the expected variation in surgically induced astigmatism among the investigators. The analysis of $\log M A R$ UCDVA was also adjusted for the effect of site. The interactions between site and treatment for dioptric reduction in cylinder and logMAR UCDVA were consequently determined not to be statistically significant $(P=0.932$ and 0.108 , respectively). 
Table 3 Toric IOL axial misalignment and rotational stability

\begin{tabular}{|c|c|c|c|c|}
\hline & \multicolumn{3}{|l|}{ Toric IOL } & \multirow[t]{2}{*}{ All Toric } \\
\hline & $\mathrm{I} .25 \mathrm{D}$ & $2.00 \mathrm{D}$ & $2.75 \mathrm{D}$ & \\
\hline \multicolumn{5}{|c|}{ Visit 4 absolute axis misalignment from surgical marking, in degrees } \\
\hline $\mathrm{N}$ & 77 & 16 & II & 104 \\
\hline Mean (SD) & $4.77(7.33)$ & $5.15(9.61)$ & $3.32(2.01)$ & $4.68(7.33)$ \\
\hline Min, Max & $0.1,57.0$ & $0.1,40.3$ & $0.3,7.5$ & $0.1,57.0$ \\
\hline $95 \%$ tolerance interval for $90 \%$ of the population & -9.25 to 18.79 & -18.28 to 28.58 & -2.19 to 8.83 & -9.02 to 18.38 \\
\hline$\leq 5^{\circ}$ misalignment, $\mathrm{n}(\%)$ & $56(72.7)$ & $13(81.3)$ & $9(81.8)$ & $78(75.0)$ \\
\hline$\leq 10^{\circ}$ misalignment, $\mathrm{n}(\%)$ & $71(92.2)$ & $15(93.8)$ & II $(100.0)$ & $97(93.3)$ \\
\hline \multicolumn{5}{|l|}{ Absolute rotation from Visit 3 to Visit 4} \\
\hline $\mathrm{N}$ & 74 & 15 & 12 & 101 \\
\hline Mean (SD) & $1.15(1.08)$ & $0.92(1.09)$ & $\mathrm{I} .08(0.73)$ & I.II (I.04) \\
\hline Min, Max & $0.0,4.6$ & $0.1,4.0$ & $0.1,2.5$ & $0.0,4.6$ \\
\hline$\leq 5^{\circ}$ rotation, $\mathrm{n}(\%)$ & $74(100.0)$ & $15(100.0)$ & $12(100.0)$ & $101(100.0)$ \\
\hline $95 \%$ exact $\mathrm{Cl}$ & $95.1 \%-100.0 \%$ & $78.2 \%-100.0 \%$ & $73.5 \%-100.0 \%$ & $96.4 \%-100.0 \%$ \\
\hline
\end{tabular}

Abbreviations: D, diopter; IOL, intraocular lens; Max, maximum; Min, minimum.

Visual acuity and posterior capsule opacification

Preoperative mean BCDVA and UCDVA were similar among groups (Table 5). At Visit 4, the mean BCDVA value was not significantly different between the control IOL group and the $1.25 \mathrm{D}$ toric IOL group $(P=0.766)$. In contrast, mean postoperative UCDVA was significantly better for the 1.25 D toric IOL group than the control IOL group at Visit $4(0.11 \pm 0.14 \log$ MAR units and $0.20 \pm 0.17$ $\log$ MAR units, respectively; $P<0.001$ ). The proportion of subjects with UCDVA $20 / 20$ or better at Visit 4 was $40.0 \%$ for the All Toric group and $16.7 \%$ for the control group. Similarly, the proportion of subjects with UCDVA 20/40 or better was $94.5 \%$ for the All Toric group and $83.3 \%$ for the control group. For all groups combined, $98.6 \%$ of the 428 EPCO values collected were 0.00 , and no EPCO value at any point was $>0.02$.

\section{Discussion}

Patients have high expectations for their quality of vision after cataract surgery, but often desire increased spectacle independence. These expectations can be met by surgical precision, accurate IOL power calculation, correction of astigmatism, and choice of IOLs that minimize dysphotopsia and PCO. This study demonstrated that the toric IOL (in the $1.25 \mathrm{D}$ group) had superior cylinder reduction $(P<0.001)$ and better UCDVA $(P<0.001)$ compared to the spherical control lens. The effectiveness of any toric IOL is contingent upon its rotational stability, and the toric IOL demonstrated $\leq 5^{\circ}$ of rotation in $100 \%$ of subjects. This outcome is superior to the rotational stability results for the AcrySof IQ Toric IOL, which reported only $90 \%$ subjects with $\leq 5^{\circ}$ rotation at 120-180 days. ${ }^{21}$ In subjects with a small amount of astigmatism, the $1.25 \mathrm{D}$ toric IOL corrected significantly

Table 4 Dioptric cylinder reduction at Visit 4 in the intent-to-treat population

\begin{tabular}{|c|c|c|c|c|c|}
\hline & \multirow{2}{*}{$\begin{array}{l}\text { Control } \\
\text { IOL } \\
(\mathbf{N}=78)\end{array}$} & \multicolumn{4}{|l|}{ Toric IOL } \\
\hline & & $\begin{array}{l}1.25 \mathrm{D} \\
(\mathrm{N}=80)\end{array}$ & $\begin{array}{l}2.00 \mathrm{D} \\
(\mathrm{N}=18)\end{array}$ & $\begin{array}{l}2.75 \mathrm{D} \\
(\mathrm{N}=12)\end{array}$ & $\begin{array}{l}\text { All Toric group } \\
(\mathrm{N}=|| 0)\end{array}$ \\
\hline Mean reduction $( \pm S D)$ & $0.479 \pm 0.665$ & $0.865 \pm 0.487$ & $\mathrm{I} .4 \mathrm{I} 3 \pm 0.532$ & $1.944 \pm 0.327$ & $1.072 \pm 0.601$ \\
\hline Median & 0.525 & 0.930 & 1.605 & 1.910 & 1.055 \\
\hline Min, Max & $-1.14,1.76$ & $-0.78,1.78$ & $-0.14,2.02$ & $1.40,2.49$ & $-0.78,2.49$ \\
\hline Missing data & I & 0 & 2 & 0 & 2 \\
\hline Treatment effect & & 0.39 & & & \\
\hline $95 \% \mathrm{Cl}$ of effect & & $0.228-0.545$ & & & \\
\hline Multiple imputation $P$-value & & $<0.001$ & & & \\
\hline Within $0.50 \mathrm{D}$ of intended, $\mathrm{n}(\%)$ & $27(34.6)$ & $43(53.8)$ & $12(66.7)$ & $8(66.7)$ & $63(57.3)$ \\
\hline $95 \%$ exact $\mathrm{Cl}$ & $24.2 \%-46.2 \%$ & $42.2 \%-65.0 \%$ & $41.0 \%-86.7 \%$ & $34.9 \%-90.1 \%$ & $47.5 \%-66.7 \%$ \\
\hline Within I.00 D of intended, $n(\%)$ & $45(57.7)$ & 7I (88.8) & $17(94.4)$ & $12(100.0)$ & $100(90.9)$ \\
\hline $95 \%$ exact $\mathrm{Cl}$ & $46.0 \%-68.8 \%$ & $79.7 \%-94.7 \%$ & $72.7 \%-99.9 \%$ & $73.5 \%-100.0 \%$ & $83.9 \%-95.6 \%$ \\
\hline
\end{tabular}

Abbreviations: D, diopter; IOL, intraocular lens; Max, maximum; Min, minimum. 
Table 5 Visual acuity

\begin{tabular}{|c|c|c|c|c|c|}
\hline & \multirow[t]{2}{*}{ Control IOL } & \multicolumn{3}{|l|}{ Toric IOL } & \multirow[t]{2}{*}{ All Toric } \\
\hline & & $1.25 \mathrm{D}$ & $2.00 \mathrm{D}$ & $2.75 \mathrm{D}$ & \\
\hline \multicolumn{6}{|c|}{ Preoperative logMAR BCDVA } \\
\hline $\mathrm{n}$ & 79 & 80 & 20 & 12 & 112 \\
\hline Mean (SD) & $0.48(0.23)$ & $0.50(0.19)$ & $0.58(0.36)$ & $0.52(0.21)$ & $0.52(0.23)$ \\
\hline \multicolumn{6}{|c|}{ Preoperative Snellen BCDVA, $n(\%)$} \\
\hline $20 / 20$ or better & 0 & 0 & 0 & 0 & 0 \\
\hline $20 / 25$ or better & 0 & 0 & 0 & 0 & 0 \\
\hline $20 / 32$ or better & $\mathrm{I}(\mathrm{I} .3)$ & 0 & 0 & 0 & 0 \\
\hline $20 / 40$ or better & $21(26.6)$ & $18(22.5)$ & $6(30.0)$ & $3(25.0)$ & $27(24.1)$ \\
\hline Worse than $20 / 40$ & $58(73.4)$ & $62(77.5)$ & $14(70.0)$ & $9(75.0)$ & 85 (75.9) \\
\hline \multicolumn{6}{|c|}{ Visit 4 logMAR BCDVA } \\
\hline $\mathrm{n}$ & 78 & 80 & 18 & 12 & 110 \\
\hline Mean (SD) & $0.01(0.09)$ & $0.00(0.09)$ & $0.05(0.10)$ & $-0.01(0.09)$ & $0.01(0.09)$ \\
\hline \multicolumn{6}{|c|}{ Visit 4 Snellen BCDVA, $n(\%)$} \\
\hline $20 / 20$ or better & $60(76.9)$ & $60(75.0)$ & $10(55.6)$ & $10(83.3)$ & $80(72.7)$ \\
\hline $20 / 25$ or better & $74(94.9)$ & $77(96.3)$ & $16(88.9)$ & $12(100.0)$ & $105(95.5)$ \\
\hline $20 / 32$ or better & 77 (98.7) & $79(98.8)$ & $18(100.0)$ & $12(100.0)$ & $109(99.1)$ \\
\hline $20 / 40$ or better & $78(100.0)$ & $79(98.8)$ & $18(100.0)$ & $12(100.0)$ & $109(99.1)$ \\
\hline Worse than $20 / 40$ & 0 & $\mathrm{I}(\mathrm{I} .3)$ & 0 & 0 & $\mathrm{I}(0.9)$ \\
\hline \multicolumn{6}{|l|}{ Control vs toric I.25 D } \\
\hline$P$-value & & 0.766 & & & \\
\hline \multicolumn{6}{|c|}{ Preoperative logMAR UCDVA } \\
\hline $\mathrm{n}$ & 79 & 80 & 17 & 12 & 109 \\
\hline Mean (SD) & $0.63(0.34)$ & $0.62(0.28)$ & $0.72(0.38)$ & $0.73(0.30)$ & $0.64(0.30)$ \\
\hline \multicolumn{6}{|c|}{ Preoperative Snellen UCDVA, n (\%) } \\
\hline $20 / 20$ or better & 0 & 0 & I (5.9) & 0 & $\mathrm{I}(0.9)$ \\
\hline $20 / 25$ or better & $3(3.8)$ & $\mathrm{I}(\mathrm{I} .3)$ & I (5.9) & 0 & $2(1.8)$ \\
\hline $20 / 32$ or better & $7(8.9)$ & $4(5.0)$ & I (5.9) & 0 & $5(4.6)$ \\
\hline $20 / 40$ or better & $18(22.8)$ & $10(12.5)$ & I (5.9) & $\mathrm{I}(8.3)$ & $12(11.0)$ \\
\hline Worse than $20 / 40$ & $61(77.2)$ & $70(87.5)$ & $16(94.1)$ & II (9I.7) & $97(89.0)$ \\
\hline \multicolumn{6}{|l|}{ Visit 4 logMAR UCDVA } \\
\hline $\mathrm{n}$ & 78 & 80 & 18 & 12 & 110 \\
\hline Mean (SD) & $0.19(0.16)$ & $0.11(0.14)$ & $0.12(0.11)$ & $0.13(0.18)$ & $0.11(0.14)$ \\
\hline Multiple imputation & & $<0.001$ & & & \\
\hline \multicolumn{6}{|c|}{ Visit 4 Snellen UCDVA, $\mathrm{n}(\%)$} \\
\hline $20 / 20$ or better & $13(16.7)$ & $36(45.0)$ & $4(22.2)$ & $4(33.3)$ & $44(40.0)$ \\
\hline $20 / 25$ or better & 37 (47.4) & $49(61.3)$ & $12(66.7)$ & $7(58.3)$ & $68(61.8)$ \\
\hline $20 / 32$ or better & $53(67.9)$ & $66(82.5)$ & $16(88.9)$ & $10(83.3)$ & $92(83.6)$ \\
\hline $20 / 40$ or better & $65(83.3)$ & $76(95.0)$ & $18(100.0)$ & $10(83.3)$ & $104(94.5)$ \\
\hline Worse than $20 / 40$ & $13(16.7)$ & $4(5.0)$ & 0 & $2(16.7)$ & $6(5.5)$ \\
\hline
\end{tabular}

Abbreviations: BCDVA, best-corrected distance visual acuity; D, diopter; IOL, intraocular lens; logMAR, logarithm of the minimum angle of resolution; Max, maximum; Min, minimum; UCDVA, uncorrected distance visual acuity.

more astigmatism $(0.39 \mathrm{D})$ than the correction produced by the corneal incision on the steep axis alone in the control group $(P<0.001)$. As a result, the likelihood of achieving excellent 20/20 UCDVA was nearly 2.5 times greater in subjects implanted with the $1.25 \mathrm{D}$ toric IOL (40\%) than the control IOL (16.7\%). These findings are consistent with the results reported in two smaller-scale studies ( $\mathrm{n}=23$ eyes and $\mathrm{n}=21$ eyes, respectively), which concluded that the enVista MX60T Toric IOL provided excellent refractive and visual outcomes associated with clinically significant rotational stability and cylinder reduction. ${ }^{22,23}$
AEs in this study were below the ISO standard 11979-7 historical AE grid rates. In addition, toric IOLs are more likely to require secondary surgical intervention than spherical IOLs because of the potential for misalignment and rotation. The cumulative rate of secondary surgical intervention through 6 months for the MX60T Toric IOL $(0.0 \%)$ compares favorably with reported rates for the AcrySof Toric $(1.6 \%)^{24}$ and Tecnis Toric (3.4\%) IOLs. ${ }^{25}$ The MX60T Toric IOL shares with its parent model aspheric aberration-free optics, scratch resistance, and a posterior square edge design to minimize PCO. There were no reports of photophobia, glare and halos, 
or other visual disturbances in the enVista MX60 IOL group and $<1 \%$ in the enVista MX60T Toric IOL group in this study. PCO occurred in $\sim 1 \%$ of eyes in both groups cumulatively through 6 months.

A limitation of this study is that glistenings were not evaluated; however, the incidence of glistenings was evaluated in 122 subjects implanted with the parent MX60 IOL in a pivotal, 6-month, multicenter trial. ${ }^{8}$ In that study, no glistenings were reported at any visit. It is anticipated that the enVista MX60T Toric IOL is also glistening-free because it is composed of the same material as the parent lens, only differing in the addition of the toric optic and axis marks. The enVista MX60T Toric IOL material, like that of the parent MX60 IOL, has a relatively higher water content than other hydrophobic IOLs, allowing sufficient prehydration to prevent glistening formation. ${ }^{7}$ Considering that glistenings can occur beyond 6 months, ${ }^{13,15}$ additional studies evaluating the rate of glistenings with the enVista MX60T Toric IOL at up to 1-year postimplantation, and as compared to other IOLs, are warranted.

\section{Conclusion}

The enVista MX60T Toric IOL was safe and effective in meeting the needs of patients desiring correction of astigmatism at the time of cataract surgery.

\section{Acknowledgments}

Writing assistance by Heather S. Oliff, $\mathrm{PhD}$ (Science Consulting Group LLC, North Tustin, CA, USA), statistical analysis by Gary Mosehauer, MS (Bausch \& Lomb, Incorporated), proofreading by Jennifer Laskowski (Valeant Pharmaceuticals LLC North America, Bridgewater, NJ, USA), and investigative support from the enVista Toric Clinical Study Group (Chad L. Betts, MD, Fayetteville, AK; Keith Charles, MD, Mount Dora, FL; Gary Foster, MD, Fort Collins, CO; Luther L. Fry, MD, Garden City, KS; Joseph Gira, MD, St Louis, MO; James A. Katz, MD, Des Plaines, IL; Kevin Lavery, MD, Jackson, MI; John Millin, MD, Louisville, KY; Farrell C. Tyson, MD, Cape Coral, FL; Robert Weinstock, MD, Largo, FL). The study was funded by Bausch \& Lomb Inc.; Rochester, NY, USA.

\section{Disclosure}

Dr Williams and Dr Hope are employees of Bausch \& Lomb; Dr Packer and Dr Feinerman are consultants to Bausch \& Lomb. The authors report no other conflicts of interest in this work.

\section{References}

1. Ferrer-Blasco T, Montes-Mico R, Peixoto-de-Matos SC, GonzalezMeijome JM, Cervino A. Prevalence of corneal astigmatism before cataract surgery. J Cataract Refract Surg. 2009;35(1):70-75.
2. Hoffer KJ. Biometry of 7,500 cataractous eyes. Am J Ophthalmol. 1980; 90(3):360-368.

3. Lehmann RP, Houtman DM. Visual performance in cataract patients with low levels of postoperative astigmatism: full correction versus spherical equivalent correction. Clin Ophthalmol. 2012;6:333-338.

4. Wilkins MR, Allan B, Rubin G, Moorfields IOLSG. Spectacle use after routine cataract surgery. Br J Ophthalmol. 2009;93(10):1307-1312.

5. Nichamin LD. Astigmatism control. Ophthalmol Clin North Am. 2006;19(4):485-493.

6. Rubenstein JB, Raciti M. Approaches to corneal astigmatism in cataract surgery. Curr Opin Ophthalmol. 2013;24(1):30-34.

7. Packer M. enVista hydrophobic acrylic intraocular lens: glistening free. Exp Rev Ophthalmol. 2015;10(5):415-420.

8. Packer M, Fry L, Lavery KT, et al. Safety and effectiveness of a glistening-free single-piece hydrophobic acrylic intraocular lens (enVista). Clin Ophthalmol. 2013;7:1905-1912.

9. Packer M, Rajan M, Ligabue E, Heiner P. Clinical properties of a novel, glistening-free, single-piece, hydrophobic acrylic IOL. Clin Ophthalmol. 2014;8:421-427.

10. Bausch+Lomb enVista hydrophobic acrylic intraocular lens Directions for Use. Available from: http://www.bausch.com/Portals/77/-/m/BL/ Global/dfu/4130300.pdf?ver=2017-08-14-111156-240. Accessed May 02, 2018.

11. Mamalis N. Intraocular lens glistenings. J Cat Refract Surg. 2012;38: $1119-1120$.

12. Gunenc U, Oner FH, Tongal S, Ferliel M. Effects on visual function of glistenings and folding marks in AcrySof intraocular lenses. J Cataract Refract Surg. 2001;27(10):1611-1614.

13. Waite A, Faulkner N, Olson RJ. Glistenings in the single-piece, hydrophobic, acrylic intraocular lenses. Am J Ophthalmol. 2007;144(1): 143-144.

14. Xi L, Liu Y, Zhao F, Chen C, Cheng B. Analysis of glistenings in hydrophobic acrylic intraocular lenses on visual performance. Int $J$ Ophthalmol. 2014;7(3):446-451.

15. Colin J, Praud D, Touboul D, Schweitzer C. Incidence of glistenings with the latest generation of yellow-tinted hydrophobic acrylic intraocular lenses. J Cataract Refract Surg. 2012;38(7):1140-1146.

16. Apple DJ, Escobar-Gomez M, Zaugg B, Kleinmann G, Borkenstein AF. Modern cataract surgery: unfinished business and unanswered questions. Surv Ophthalmol. 2011;56(6 Suppl):S3-S53.

17. Cisneros-Lanuza A, Hurtado-Sarrio M, Duch-Damper A, GallegoPinazo R, Menezo-Rozalen JL. Glistenings in the Artiflex phakic intraocular lens. J Cataract Refract Surg. 2007;33:1405-1408.

18. International Organization for Standardization. ISO 11979-7:2006. Ophthalmic Implants - Intraocular lenses - Part 7: Clinical investigations, Annex B.3. 2006.

19. Tetz MR, Auffarth GU, Sperker M, Blum M, Volcker HE. Photographic image analysis system of posterior capsule opacification. $J$ Cataract Refract Surg. 1997;23(10):1515-1520.

20. American National Standards Institute. ANSI. Z80.30-2010. Ophthalmics - Toric Intraocular Lenses.

21. Alcon Laboratories. Acrysof IQ Toric Astigmatism IOL (package insert). Fort Worth, TX: Alcon Laboratories; 2009.

22. Garzon N, Poyales F, de Zarate BO, Ruiz-Garcia JL, Quiroga JA. Evaluation of rotation and visual outcomes after implantation of monofocal and multifocal toric intraocular lenses. J Refract Surg. 2015; 31(2):90-97.

23. Torio KC, Ang RET, Martinez GHA, Remo JTM. Comparison of the rotational stability of different toric intraocular lens implants. Phillippine J Ophthal. 2014;39(2):67-72.

24. Summary of Safety and Effectiveness Data. ACRYSOF ${ }^{\circledR}$ Single-Piece Posterior Chamber Intraocular Lenses With Toric Optic. Available from: https://www.accessdata.fda.gov/cdrh_docs/pdf/P930014S045b. pdf. Accessed December 13, 2017.

25. Summary of Safety and Effectiveness Data. TECNIS ${ }^{\circledR}$ Toric 1-Piece Intraocular Lens. Available from: https://www.accessdata.fda.gov/ cdrh_docs/pdf/P980040S039b.pdf. Accessed December 13, 2017. 
Clinical Ophthalmology

\section{Publish your work in this journal}

Clinical Ophthalmology is an international, peer-reviewed journal covering all subspecialties within ophthalmology. Key topics include: Optometry; Visual science; Pharmacology and drug therapy in eye diseases; Basic Sciences; Primary and Secondary eye care; Patien Safety and Quality of Care Improvements. This journal is indexed on

PubMed Central and CAS, and is the official journal of The Society of Clinical Ophthalmology (SCO). The manuscript management system is completely online and includes a very quick and fair peer-review system, which is all easy to use. Visit http://www.dovepress.com/ testimonials.php to read real quotes from published authors. 